\title{
Successful primary percutaneous coronary intervention determines the very long-term prognosis in ST-segment elevation myocardial infarction even in survivors of the acute phase. The ANIN Myocardial Infarction Registry
}

\author{
Magdalena Polańska-Skrzypczyk, Maciej Karcz, Witold Rużyłło, Adam Witkowski \\ Department of Interventional Cardiology and Angiology, Institute of Cardiology, Warsaw, Poland
}

Adv Interv Cardiol 2019; 15, 3 (57): 283-291

DOI: https://doi.org/10.5114/aic.2019.87881

\begin{abstract}
A bstract
Introduction: Successful primary percutaneous coronary intervention (pPCl) saves lives in the acute phase of ST-elevation myocardial infarction (STEMI) and improves the mid-term prognosis. Whether that benefit remains significant in very long-term follow-up and is associated with total ischaemic time (TIT), especially in survivors of the acute phase of STEMI, is unknown.

Aim: We sought to investigate the impact of initial and final thrombolysis in myocardial infarction (TIMI) flow on long-term survival in a homogeneous, unselected group of patients with STEMI undergoing $\mathrm{pPCl}$ at a high-volume centre.

Material and methods: All consecutive STEMI patients treated with $\mathrm{PPCl}$ in our tertiary centre were enrolled in the ANIN Myocardial Infarction Registry.

Results: Among 1064 patients 871 (82\%) had an occluded infarct artery (IRA) at baseline, while pPCI was successful in 885 (83\%) patients. At 9 years all-cause and cardiovascular (CV) mortality were 28\% (294 patients) and 19\% (196 patients), respectively. Failure of $\mathrm{pPCl}$ was an independent predictor of long-term all-cause and CV mortality $(\mathrm{OR}=1.5,95 \% \mathrm{Cl}: 1.1-2.0, p=0.03$ and $\mathrm{OR}=$ $1.8,95 \% \mathrm{Cl}: 1.3-2.7, p=0.001$, respectively). In survivors of the acute phase, occluded IRA at baseline was an independent predictor of all-cause mortality $(\mathrm{OR}=1.5,95 \% \mathrm{Cl}: 1.0-2.3, p=0.04)$, while $\mathrm{pPCl}$ failure predicted $\mathrm{CV}$ mortality $(\mathrm{OR}=1.8,95 \% \mathrm{Cl}: 1.2-2.8, p=$ $0.005)$. Mortality rate increased with TIT even in patients with $\mathrm{pPCl}$ success.

Conclusions: Angiographic results of $\mathrm{pPCl}$ determine the very long-term survival of STEMI patients, even in survivors of the acute phase of STEMI. Shortening of TIT is crucial.

Key words: long-term survival, ST-elevation myocardial infarction, primary percutaneous coronary intervention, thrombolysis in myocardial infarction flow.

S u m m a ry

Based on 9-year follow-up of 1064 consecutive patients with ST-segment elevation myocardial infarction (STEMI) treated with primary percutaneous coronary intervention $(\mathrm{pPCl})$ we demonstrated unexpectedly good prognosis of those patients. Over $70 \%$ of patients were alive at the end of follow-up and over $80 \%$ did not experience cardio-vascular death. Angiographic results of $\mathrm{pPCl}$ were associated with very long-term survival, even after exclusion of patients who deceased by day 30 . Only final thrombolysis in myocardial infarction (FTIMI) 3 flow, but not TIMI 2 flow improved 9-year prognosis. Very long-term clinical outcomes were best in patients with patent infarct related artery (IRA) both at baseline and after pPCI. Finally, although longer total ischaemic time (TIT) was associated with higher rate of IRA patency at baseline, it was also associated with smaller procedural success rate and poorer survival. Even in patients with final TIMI 3 flow prognosis declined with increasing TIT.
\end{abstract}

\section{Introduction}

It is well documented that successful primary percutaneous coronary intervention ( $\mathrm{PPCl}$ ) saves lives in the acute phase of ST-elevation myocardial infarction (STEMI) and improves mid-term prognosis. Both in-hospital and midterm mortality are significantly lower in comparison with fibrinolytic treatment (relative reduction in risk 39\% and

\section{Corresponding author:}

Magdalena Polańska-Skrzypczyk MD, Department of Interventional Cardiology and Angiology, Institute of Cardiology, 42 Alpejska St, 04-628 Warsaw, Poland, e-mail: magdapolanska@gmail.com

Received: 4.02.2019, accepted: 7.04.2019. 
$27 \%$, respectively) $[1,2]$. This is primarily due to the lower incidence of full recanalisation during fibrinolysis [3].

Successful pPCI results in up to $98 \%$ in-hospital and 95\% 1-year survival in clinical trials that exclude highrisk patients [4]. Despite the high rate of successful $\mathrm{pPCl}$, prognosis varies widely. Survival with regard to $\mathrm{PPCl}$ results and total ischaemic time (TIT) has not been well established although a meta-analysis of fibrinolytic trials confirmed lower survival rates with increasing TIT, which was partly explained by decreasing efficacy of lysis with treatment delay [5].

Furthermore, there are limited data on whether those benefits remain significant in the very long-term follow-up. Some data presented previously were related to the long-term observation but a heterogeneous group of patients [6].

The prognostic significance of $\mathrm{pPCl}$ results in survivors of the acute phase of STEMI is uncertain, while it is known that the risk of death is highest during the first month after STEMI and declines over time [6].

\section{Aim}

We sought to investigate the impact of initial and final thrombolysis in myocardial infarction (TIMI) flow on long-term survival considering TIT, the cause of death and to determine independent factors associated with $\mathrm{pPCl}$ results in a homogeneous, unselected group of patients with STEMI undergoing $\mathrm{PPCl}$ at a high-volume centre.

\section{Material and methods}

A prospective, single-centre ANIN Myocardial Infarction Registry was set up at the Institute of Cardiology in Warsaw enrolling all consecutive STEMI patients undergoing $\mathrm{PPCl}$ between February 2001 and October 2002, which was previously described in detail [7, 8]. Of note, since February 2001, coronary angiography and $\mathrm{pPCl}$ whenever indicated have been the sole method of reperfusion in STEMI patients in our tertiary centre. Clinical, angiographic and procedural data were prospectively collected. There were no exclusion criteria; particularly, patients with advanced age, cardiogenic shock, pulmonary oedema or known renal dysfunction were not excluded. TIT was defined as the time from symptom onset to $\mathrm{pPCl}$.

Primary angioplasty was performed in all patients in compliance with concurrent standards. Except for patients in cardiogenic shock, only the infarct-related artery (IRA) was recanalised. Bare metal stents (BMS) were implanted in all significant stenoses in the IRA, unless the artery tortuosity, massive calcification or small diameter precluded stenting and plain balloon angioplasty was performed. No manual or mechanical thrombectomy was used at that time. Rescue abciximab was administered in case of angiographic evidence of massive thrombus, slow or no-reflow or thromboembolic complications of $\mathrm{pPCl}$.
All patients received combination of acetyl salicylic acid with clopidogrel or ticlopidine.

According to initial TIMI flow (iTIMI) patients were divided into two groups: the occluded IRA group (iTIMI flow 0 or 1 ) and the patent IRA group (iTIMI flow 2 or 3). Procedural success was defined as final TIMI (fTIMI) flow 3, while failure was defined as a fTIMI 0 to 2 flow. Major adverse cardiac and cerebrovascular events (MACCEs) were defined according to generally approved criteria (reinfarction, stroke, major bleeding and in-hospital mortality). Renal dysfunction was defined as estimated glomerular filtration rate (eGFR) below $60 \mathrm{ml} / \mathrm{min} / 1.73 \mathrm{~m}^{2}$ [9].

Thirty-day and 1-year survival (respectively short- and mid-term survival) were verified by telephone calls to patients or their cardiologists. Long-term mortality data, including cause of death, were obtained from the National Census Registry. Cardiovascular cause of death was defined according to the Tenth Revision of International Classification of Disease (ICD-10) as described before [10]

Patients who were alive after day 30 formed the subgroup of survivors of the acute phase.

The study complies with the Declaration of Helsin$\mathrm{ki}$ and its research protocol was approved by the ethics committee.

\section{Statistical analysis}

Typical statistical methods were used and previously described [7, 8]. Time-to-event data were summarised as Kaplan-Meier estimates and compared with the log-rank test. To adjust for baseline differences between study groups, all variables potentially associated with the clinical endpoint were tested in multivariate analyses; the Cox proportional hazards model (forward stepwise variable) was used to identify independent predictors of mortality. Results were presented as hazard ratios (HRs) with 95\% confidence intervals (Cls). All statistical analyses were performed using SPSS version 17.0 (SPSS Inc, Chicago, IL, USA).

\section{Results}

\section{Baseline characteristics}

A total of 1064 consecutive patients with STEMI underwent coronary angiography and were treated with $\mathrm{pPCl}$. Clinical and demographic characteristics of studied patients, which were typical for STEMI cohort of patients, are shown in Table I. Total ischaemic time was shorter than $3 \mathrm{~h}$ in 350 (33\%) patients, ranged between 3 and $6 \mathrm{~h}$ in 461 (44\%) patients and exceeded $6 \mathrm{~h}$ in 186 (18\%) patients.

\section{Angiographic characteristics and procedural results}

Angiographic characteristics and procedural results were typical for a cohort of STEMI patients treated with $\mathrm{pPCl}$. The numbers of patients with iTIMI 0, 1, 2 and 3 flow were 797 (75\%), 74 (7\%), 97 (9\%) and 96 (9\%), re- 
Table I. Baseline and angiographic characteristics of patients according to initial and final TIMI flow

\begin{tabular}{|c|c|c|c|c|c|c|c|}
\hline Parameter (\%) & $\begin{array}{l}\text { All patients } \\
(n=1064)\end{array}$ & $\begin{array}{c}\text { Patients with } \\
\text { iTIMI < } 2 \\
(n=871) \\
\end{array}$ & $\begin{array}{l}\text { Patients with } \\
\text { iTIMI } \geq 2 \\
(n=193)\end{array}$ & $P$-value & $\begin{array}{c}\text { Patients with } \\
\text { fTIMI < } 3 \\
(n=177)\end{array}$ & $\begin{array}{c}\text { Patients with } \\
\text { fTIMI } 3 \\
(n=885)\end{array}$ & $P$-value \\
\hline Age & $60 \pm 12$ & $60 \pm 12$ & $60 \pm 11$ & 0.38 & $60 \pm 12$ & $58 \pm 10$ & 0.04 \\
\hline Female & $283(27)$ & $235(27)$ & $48(25)$ & 0.58 & $55(31)$ & $228(26)$ & 0.16 \\
\hline $\mathrm{H} / \mathrm{O} C A D$ & $458(43)$ & $357(41)$ & $101(53)$ & 0.005 & $84(48)$ & $373(42)$ & 0.21 \\
\hline $\mathrm{H} / \mathrm{O} \mathrm{Ml}$ & $218(21)$ & $174(20)$ & $44(23)$ & 0.57 & $48(27)$ & $170(19)$ & 0.02 \\
\hline $\mathrm{H} / \mathrm{O}$ hypertension & $501(48)$ & $405(47)$ & $96(50)$ & 0.42 & $90(51)$ & $412(47)$ & 0.32 \\
\hline Diabetes mellitus & $138(13)$ & $107(12)$ & $31(16)$ & 0.15 & $27(15)$ & $111(13)$ & 0.34 \\
\hline Current smokers & $528(50)$ & $443(51)$ & $85(44)$ & 0.09 & $57(32)$ & $470(53)$ & $<0.0005$ \\
\hline Renal dysfunction & $318(36)$ & $261(36)$ & $57(35)$ & 0.91 & $66(47)$ & $252(34)$ & 0.004 \\
\hline Heart rate & $80 \pm 20$ & $80 \pm 20$ & $80 \pm 19$ & 0.81 & $79 \pm 19$ & $82 \pm 19$ & 0.04 \\
\hline SBP & $133 \pm 30$ & $130 \pm 30$ & $136 \pm 30$ & 0.54 & $132 \pm 29$ & $137 \pm 31$ & 0.23 \\
\hline Killip class $>1$ & $130(12)$ & $108(13)$ & $22(12)$ & 0.69 & $29(16)$ & $101(12)$ & 0.07 \\
\hline Cardiogenic shock & $43(4)$ & $36(4)$ & $7(4)$ & 0.74 & 19 (11) & $24(3)$ & $<0.0005$ \\
\hline Unconscious & $38(4)$ & $33(4)$ & $5(3)$ & 0.52 & $14(8)$ & $24(3)$ & 0.003 \\
\hline $\mathrm{TIT}>3 \mathrm{~h}$ & $646(61)$ & $511(59)$ & $135(70)$ & 0.02 & $118(67)$ & $528(60)$ & 0.03 \\
\hline MVD & $564(53)$ & $467(54)$ & $97(51)$ & 0.47 & $108(61)$ & $456(52)$ & 0.03 \\
\hline Stent implantation & $815(77)$ & $654(76)$ & $161(84)$ & 0.14 & $97(54)$ & $718(82)$ & $<0.0005$ \\
\hline Planned abciximab & $320(30)$ & $269(31)$ & $51(27)$ & 0.22 & $43(25)$ & $277(32)$ & 0.07 \\
\hline Rescue abciximab & $172(16)$ & $153(18)$ & $19(10)$ & 0.007 & $57(33)$ & 115 (13) & $<0.0005$ \\
\hline fTIMI 3 flow & $885(83)$ & $706(81)$ & $179(93)$ & $<0.0005$ & - & - & - \\
\hline
\end{tabular}

Values are $n(\%)$ or mean \pm SD. iTIMI - initial thrombolysis in myocardial infarction flow, fTIMI - final thrombolysis in myocardial infarction flow, H/O CAD - history of coronary artery disease, H/O MI - history of myocardial infarction, SBP-systolic blood pressure, TIT - total ischaemic time, h-hours, MVD - multivessel disease.

spectively. Patients with patent compared to occluded IRA more often had a history of CAD and longer TIT. There were no differences in the prevalence of renal dysfunction, diabetes mellitus, hypertension, Killip class $>1$, cardiogenic shock or multivessel disease (Table I).

In most patients, only the IRA was treated. Final TIMI 0, 1, 2, 3 flow was observed in 66 (6\%), 31 (3\%), 80 (8\%) and $885(83 \%)$ patients, respectively. Procedural results of two patients were missing. As shown in Table I procedural success was achieved more often in younger patients, current smokers, with shorter TIT and patent IRA at baseline. In contrast, success was achieved less often in patients with a history of myocardial infarction, renal dysfunction, multivessel disease and index STEMI complicated by cardiogenic shock.

Patients with TIT exceeding $3 \mathrm{~h}$ had a lower incidence of occluded IRA at baseline (79\% vs. $86 \%, p=0.006)$ but a lower procedural success rate $(82 \%$ vs. $87 \%, p=0.03)$. In those patients, but not in patients with TIT $<3 \mathrm{~h}$, initial IRA patency was found to be the strongest predictor of fTIMI 3 flow.

\section{Clinical outcomes}

During a mean of $8 \pm 7$ days of hospitalisation, MACCEs occurred in $63(6 \%)$ patients. Major bleeding occurred more often in patients with $\mathrm{PCl}$ failure, independently of iTIMI flow or abciximab administration $(p=0.6)$ (Table II). Procedural failure was found to be an independent risk factor of major bleeding.

For censored observations duration of follow-up ranged from 7 to 9 years. Five patients were lost to follow-up. In the final analysis 1057 patients were included. All-cause and CV mortality rates are shown in Table III. Of note, over $70 \%$ of patients were alive at the end of follow-up and over $80 \%$ did not experience CV death. Over time the percentage of CV deaths among all deaths decreased substantially from $100 \%$ in hospital, over $87 \%$ at 1 month, $79 \%$ at 1 year to $66 \%$ at 9 years of follow-up.

An association between iTIMI flow and survival was observed only with all-cause but not cardiovascular mortality and only towards the end of the follow-up period, but still iTIMI was not an independent predictor of mor- 
Table II. In-hospital MACCEs and overall mortality according to initial and final TIMI flow

\begin{tabular}{|c|c|c|c|c|c|c|c|c|c|}
\hline Parameter & $\begin{array}{c}\text { All } \\
\text { patients } \\
(n=1057)\end{array}$ & $\begin{array}{c}\text { Patients } \\
\text { with iTIMI } \\
<2 \\
(n=864) \\
\end{array}$ & $\begin{array}{c}\text { Patients } \\
\text { with iTIMI } \\
\geq 2 \\
(n=193) \\
\end{array}$ & $\begin{array}{l}\text { Multivariate } \\
\text { analysis } \\
\text { OR }(95 \% \mathrm{Cl})\end{array}$ & $P$-value & $\begin{array}{c}\text { Patients } \\
\text { with fTIMI } \\
\quad<3 \\
(n=177) \\
\end{array}$ & $\begin{array}{c}\text { Patients } \\
\text { with fTIMI } \\
3 \\
(n=880) \\
\end{array}$ & $\begin{array}{l}\text { Multivariate } \\
\text { analysis } \\
\text { OR }(95 \% \mathrm{Cl})\end{array}$ & $P$-value \\
\hline \multicolumn{10}{|l|}{ MACCES: } \\
\hline re-MI & $16(2)$ & $14(2)$ & $2(1)$ & - & 0.75 & $5(3)$ & $11(1)$ & - & 0.17 \\
\hline Major bleeding & $40(4)$ & $35(4)$ & $5(3)$ & - & 0.4 & 19 (11) & $21(2)$ & $3.3(1.5-7.9)$ & 0.004 \\
\hline Stroke & $7(1)$ & $6(1)$ & $1(1)$ & - & 1.0 & $1(1)$ & $6(1)$ & - & 0.86 \\
\hline $\begin{array}{l}\text { In-hospital } \\
\text { mortality }\end{array}$ & $41(4)$ & $35(4)$ & $6(3)$ & - & 0.55 & $24(14)$ & $17(2)$ & $4.4(1.6-12.0)$ & $<0.0005$ \\
\hline \multicolumn{10}{|l|}{ All-cause mortality: } \\
\hline 30-day & $57(5)$ & $49(6)$ & $8(4)$ & - & 0.34 & $30(17)$ & $27(3)$ & $3.1(1.7-5.8)$ & $<0.0005$ \\
\hline 1-year & $86(8)$ & $74(8)$ & $12(6)$ & - & 0.21 & $36(20)$ & $50(6)$ & $2.5(1.5-4.2)$ & $<0.0005$ \\
\hline 9-year & $294(28)$ & $254(29)$ & $40(20)$ & - & 0.16 & $76(43)$ & $218(25)$ & $1.5(1.1-2.0)$ & $<0.03$ \\
\hline \multicolumn{10}{|l|}{ CV mortality: } \\
\hline 30-day & $51(5)$ & $45(5)$ & $6(3)$ & - & 0.26 & $27(15)$ & $24(3)$ & $2.9(1.5-5.5)$ & $<0.0005$ \\
\hline 1-year & $68(6)$ & $59(7)$ & $9(5)$ & - & 0.34 & $31(18)$ & $37(4)$ & $2.1(1.1-3.8)$ & 0.002 \\
\hline 9-year & $196(19)$ & $167(19)$ & $29(15)$ & - & 0.08 & $62(35)$ & $134(15)$ & $1.8(1.3-2.7)$ & $<0.0005$ \\
\hline
\end{tabular}

Values are $n(\%)$ or mean \pm SD. ITIMI - initial thrombolysis in myocardial infarction, fTIMI-final thrombolysis in myocardial infarction, re-MI - reinfarction, CV-cardiovascular, MACCES - major adverse cardiac and cerebrovascular events.

Table III. Multivariate analysis of long-term mortality

\begin{tabular}{|c|c|c|c|c|c|c|c|c|}
\hline \multirow[t]{3}{*}{ Parameter } & \multicolumn{4}{|c|}{ All patients $(n=1057)$} & \multicolumn{4}{|c|}{ Survivors of acute phase of STEMI $(n=1000)$} \\
\hline & \multicolumn{2}{|c|}{$\begin{array}{c}\text { All-cause mortality } \\
n=294(28 \%)\end{array}$} & \multicolumn{2}{|c|}{$\begin{array}{c}\text { CV mortality } \\
n=196(19 \%)\end{array}$} & \multicolumn{2}{|c|}{$\begin{array}{c}\text { All-cause mortality } \\
n=237(24 \%)\end{array}$} & \multicolumn{2}{|c|}{$\begin{array}{c}\text { CV mortality } \\
n=145(15 \%)\end{array}$} \\
\hline & $\mathrm{HR}(95 \% \mathrm{Cl})$ & $P$-value & $\mathrm{HR}(95 \% \mathrm{Cl})$ & $P$-value & $\mathrm{HR}(95 \% \mathrm{Cl})$ & $P$-value & $\mathrm{HR}(95 \% \mathrm{Cl})$ & $P$-value \\
\hline $\begin{array}{l}\text { Age (every } \\
10 \text { years) }\end{array}$ & $1.9(1.7-2.3)$ & $<0.0005$ & $1.6(1.3-1.9)$ & $<0.0005$ & $1.9(1.7-2.3)$ & $<0.0005$ & $1.8(1.5-2.2)$ & $<0.0005$ \\
\hline $\begin{array}{l}\text { Current } \\
\text { smoker }\end{array}$ & $0.7(0.6-1.3)$ & 0.02 & $0.7(0.5-1.0)$ & 0.13 & $0.6(0.4-0.9)$ & 0.006 & $0.6(0.4-0.8)$ & 0.006 \\
\hline $\mathrm{H} / \mathrm{O} \mathrm{Ml}$ & - & 0.06 & - & 0.07 & $1.6(1.1-2.2)$ & 0.005 & $2.0(1.3-2.9)$ & 0.001 \\
\hline $\begin{array}{l}\text { Heart rate } \\
\text { (every 10/') }\end{array}$ & $1.2(1.1-1.3)$ & $<0.0005$ & $1.2(1.1-1.3)$ & $<0.0005$ & $1.2(1.1-1.3)$ & $<0.0005$ & $1.3(1.1-1.4)$ & $<0.0005$ \\
\hline $\begin{array}{l}\text { Renal dys- } \\
\text { function }\end{array}$ & $1.3(1.0-1.7)$ & 0.08 & $1.7(1.2-2.4)$ & 0.003 & - & 0.09 & $1.7(1.2-2.5)$ & 0.007 \\
\hline $\begin{array}{l}\text { Diabetes } \\
\text { mellitus }\end{array}$ & $1.6(1.1-4.4)$ & 0.009 & $1.4(1.0-2.1)$ & 0.22 & $1.6(1.1-2.2)$ & 0.02 & - & 0.51 \\
\hline $\begin{array}{l}\text { Cardiogenic } \\
\text { shock }\end{array}$ & $3.2(1.9-5.2)$ & $<0.0005$ & $3.6(2.0-6.5)$ & $<0.0005$ & - & 0.11 & - & 0.27 \\
\hline TIT $>3 \mathrm{~h}$ & $1.3(1.0-1.9)$ & 0.04 & $1.4(1.0-2.0)$ & 0.04 & - & 0.25 & - & 0.41 \\
\hline MVD & $1.4(1.1-1.9)$ & 0.02 & $1.7(1.2-2.0)$ & 0.003 & - & 0.16 & - & 0.06 \\
\hline $\mathrm{iTIMI}<2$ & - & 0.89 & - & 0.2 & $1.5(1.0-2.3)$ & 0.04 & - & 0.17 \\
\hline$f T|M|<3$ & $1.5(1.1-2.0)$ & 0.03 & $1.8(1.3-2.7)$ & 0.001 & - & 0.11 & $1.8(1.2-2.8)$ & 0.005 \\
\hline
\end{tabular}

HR - hazard ratio, Cl - confidence interval, CV - cardiovascular, H/O MI - history of myocardial infarction, TIT - total ischaemic time, MVD - multivessel disease, iTIMI flow - initial TIMI flow, fTIMI flow - final TIMI flow, ns - non-significant. 
A

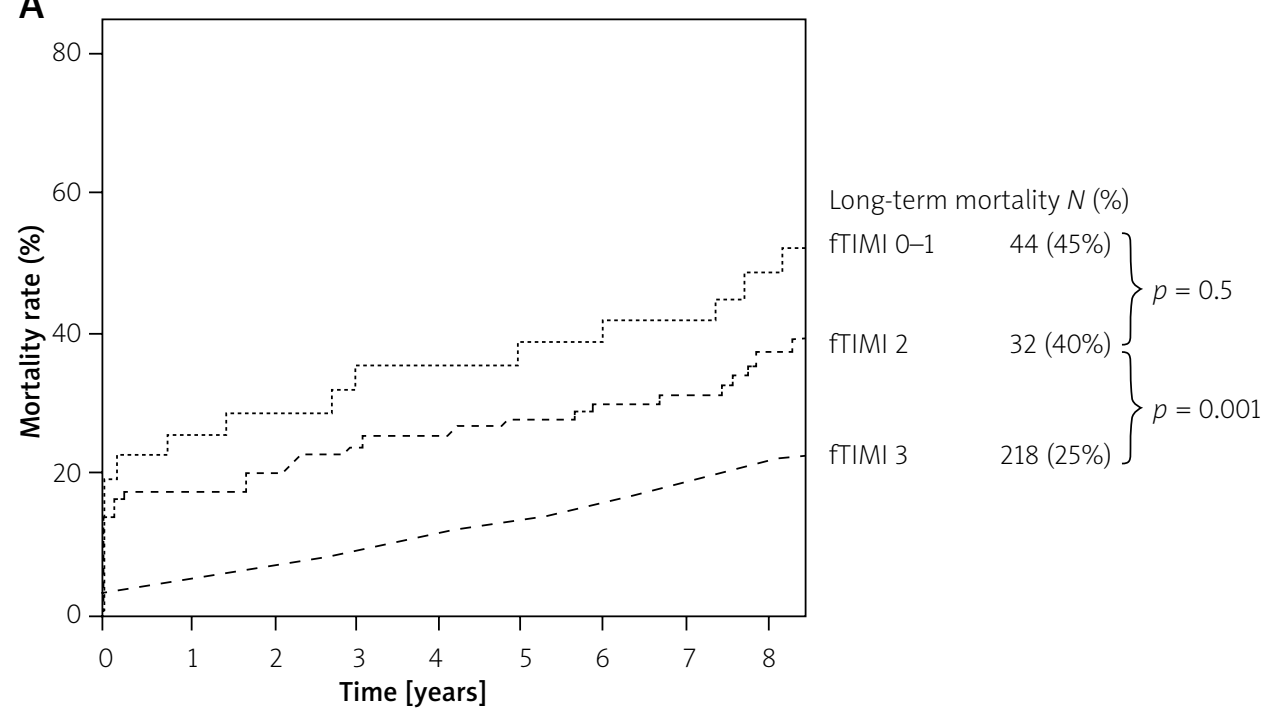

B

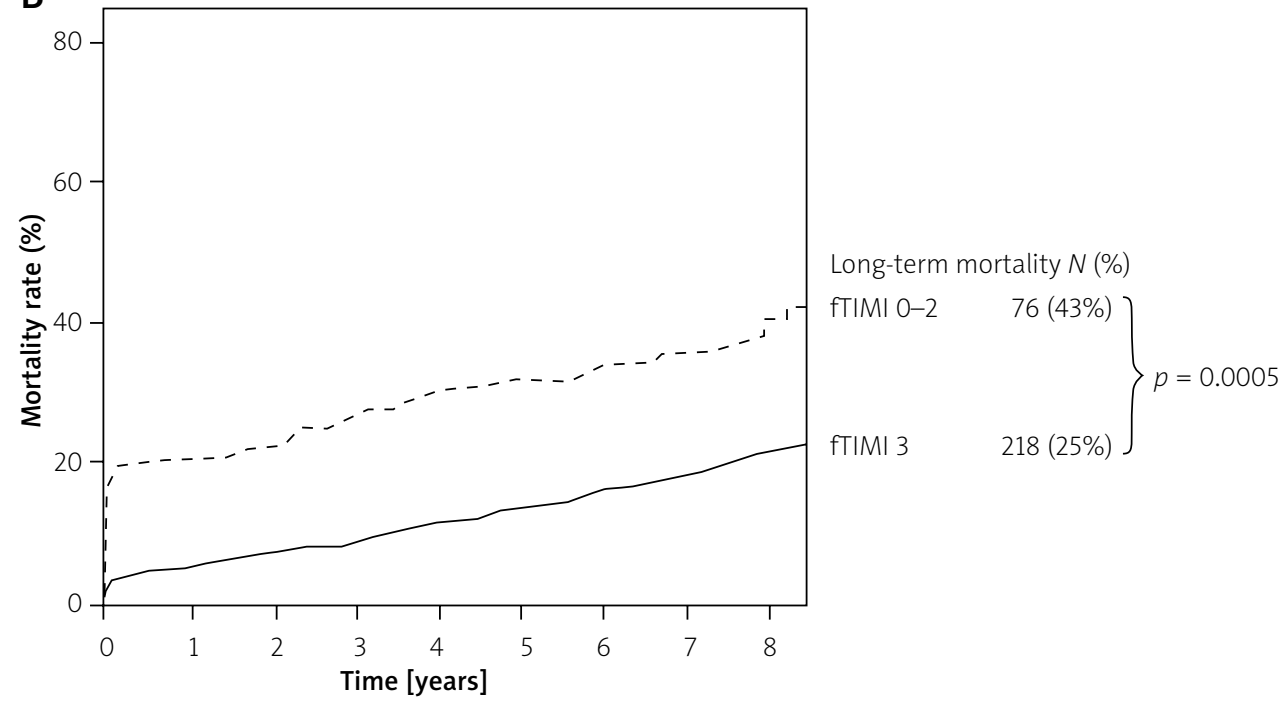

Figure 1. Kaplan-Meier curves of cumulative all-cause mortality according to fTIMI flow: A - fTIMI 0-1 vs. 2 vs. 3 flow, B - fTIMI 0-2 vs. 3 flow

tality in the whole cohort of patients (Table III). Procedural success was independently associated with all-cause and CV mortality from the beginning of observation. Results of the multivariate analysis are summarised in Table II. As depicted in Figure 1, long-term mortality was higher in patients with lower grades of fTIMI flow. However, the difference was significant only between patients with fTIMI 3 and lower (Figure 1 A). The mortality curves divided further after initial IRA patency was taken into consideration (Figure 2).

Mortality rate was strictly dependent on TIT. Among patients with procedural success, 19\% (59 patients) died with TIT shorter than 3 h, 25\% (95 patients) with TIT between 3 and 6 h, 33\% (47 patients) with TIT longer than $6 \mathrm{~h}$. It was equivalent to $24 \%$ relative reduction of mortality between groups.
Comparing patients with successful and failed $\mathrm{PCl}$ in the previously defined TIT ranges, odds ratios were 1.9 (95\% Cl: 1.1-3.4, $p=0.03$ ), 2.1 (95\% Cl: 1.4-3.1, $p<$ $0.0005)$ and $1.7(95 \% \mathrm{Cl}: 1.0-2.8, p=0.04)$, respectively.

A total of 1000 (95\%) patients survived the acute phase. At nine years all-cause and CV mortality rates in this subgroup were $24 \%(n=237)$ and $15 \%(n=145)$, respectively.

\section{Prognostic factors of long-term mortality}

After adjustment for co-variates, $\mathrm{PCl}$ failure was an independent predictor of long-term all-cause and CV mortality (Table III). In the subgroup of patients who survived the acute phase iTIMI flow was an independent predictor of all-cause mortality, and fTIMI flow was an independent predictor of CV mortality (Table III). 


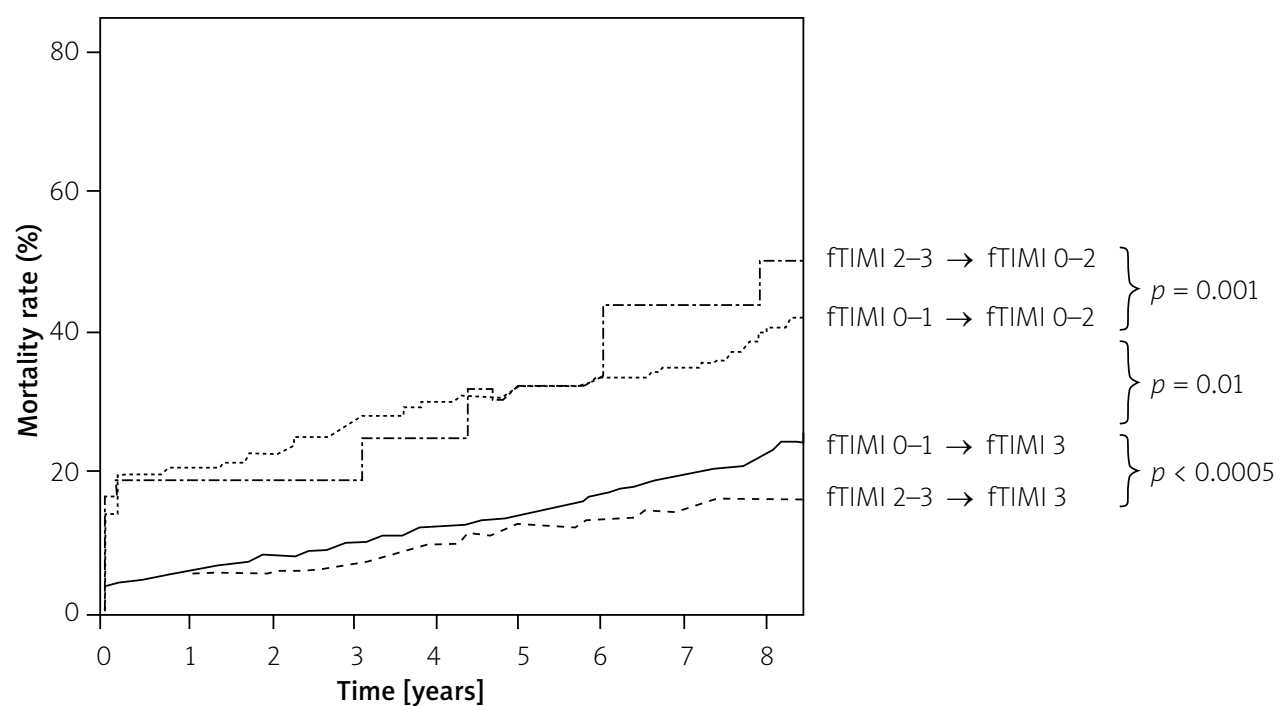

Figure 2. Kaplan-Meier curves of cumulative all-cause mortality according to ITIMI and fTIMI flow

\section{Discussion}

Results from this large prospective registry of patients with STEMI undergoing $\mathrm{PPCl}$ demonstrate the following significant findings:

1. Favourable very-long term outcomes.

2. Results of $\mathrm{pPCl}$ determine very long-term survival, including in survivors of the acute phase of STEMI.

3. Only fTIMI flow 3, but not fTIMI 2, improves prognosis.

4. Patients with patent IRA both at baseline and after $\mathrm{pPCl}$ have the most encouraging prognosis.

5. Procedural success is closely associated with iTIMI flow; however, iTIMI flow is not a predictor of all-cause mortality except in survivors of the acute phase of STEMI.

6. Longer TIT, although associated with a higher rate of patent IRA, results in less procedural success and poorer survival.

7. Even in patients with fTIMI 3 flow, prognosis declines with increasing TIT.

At the beginning, we would like to emphasise the very long period of observation of a homogeneous group of patients treated in a uniform manner and lack of exclusion criteria. To our best knowledge, the longest follow-up period of STEMI cohort patients undergoing PCI before now was 6 years [6].

Our results revealed an unexpectedly good prognosis of STEMI patients treated with $\mathrm{pPCl}$. Over $70 \%$ of patients were alive at the end of the 9-year follow-up and over $80 \%$ did not experience CV death. The mortality rate beyond the first year ranged from $2.4 \%$ to $3.7 \%$ per year, which is close to the result reported for a comparably aged broad general population cohort.

Our finding is in accordance with previously described results for short- and mid-term observation [11, 12]. We found that procedural failure, although uncommon after $\mathrm{pPCl}$, is also a predictor of very long-term mortality. More- over, very long-term prognosis was worse following $\mathrm{pPCl}$ failure even in survivors of the acute phase (K-M survivor curves diverged further beyond day 30 (Figure 3 B)). Our analysis demonstrates a fourfold greater mortality risk in patients with procedural failure in short-term, threefold in mid-term and almost twofold in long-term follow-up. It should be stressed that patients with fTIMI flow 2 have mortality rates similar to those of patients with fTIMI flow grade 0 and 1 . It suggests that only full restoration of epicardial blood flow counts. However, it appears that there is a significant difference in survival with regard to the interaction of initial TIMI flow and final TIMI flow. Mortality was lowest in patients with a patent IRA both at baseline and after $\mathrm{PCl}$, intermediate in patients with TIMI flow 3 restored after angioplasty, and highest in patients with procedural failure, especially those in whom epicardial blood flow had deteriorated.

Although initial IRA patency is associated with a higher rate of procedural success, prognosis of patients with an initially patent IRA did not differ from patients with an initially occluded IRA until the 2 last years of follow-up. A significant difference was noted only at the end of the follow-up period when more than one-third of deaths were of non-cardiovascular aetiology. However, iTIMI flow was found to be an independent risk factor for longterm all-cause mortality in survivors of the acute phase, but not CV mortality.

Our finding is at variance with a previous study in which iTIMI flow predicted early and intermediate survival [13]. In contrast to our study, patients were categorised according to iTIMI flow into groups of TIMI flow 0-2 and 3. The frequency of iTIMI 3 was twice as high, probably due to the criteria of enrolment (both STEMI and non-STEMI included). Moreover, the relationship between ITIMI flow and mortality was on the border of significance. A more recent study showed that iTIMI flow is a prognostic factor only in the case of high-risk patients 
according to TIMI risk score, whereas fTIMI flow is an independent predictor of mortality in a whole cohort of patients [14]. Another study demonstrated a significant correlation between iTIMI flow and infarct size, myocardial salvage index, and microvascular obstruction assessed by cardiac magnetic resonance, with no relation to midterm mortality [15]. Perhaps, in our study, prolonged time of observation revealed the effect of changes in the ischaemic heart disease leading to heart failure.

Furthermore, our results demonstrated a strong relationship between TIT and effect of $\mathrm{pPCl}$ and mortality. Total coronary occlusion by acute thrombus formation was more frequent during the early hours of STEMI and decreased in frequency over time due to spontaneous recanalization. In the first $3 \mathrm{~h}$ of ischaemia, the procedural success was independent of the initial TIMI flow. Only renal dysfunction, which was previously described as a predictor of procedural failure [16, 17], was associated with fTIMI flow < 3. That correlation is probably related to endothelial function, spontaneous lysis of the clot and endogenous thrombolysis, which is impaired in renal dysfunction [18]. Conversely, in patients with TIT longer than $3 \mathrm{~h}$, the most important factor associated with the procedural result is iTIMI flow. Angiographic TIMI 0 or 1 flow at presentation was associated with a fourfold higher likelihood of procedural failure, whereas the risk was twofold if the patient presented with TIMI 2 flow. The clinical benefits of spontaneous reperfusion before intervention are also time dependent. Pioneering work [19] established that in animal models the extent of myocardial necrosis could be reduced by early reperfusion of the myocardium after a coronary occlusion. Probably TIT below $3 \mathrm{~h}$ was associated with limited myocardium cell damage, while exceeding that time might lead to poor tissue perfusion

A

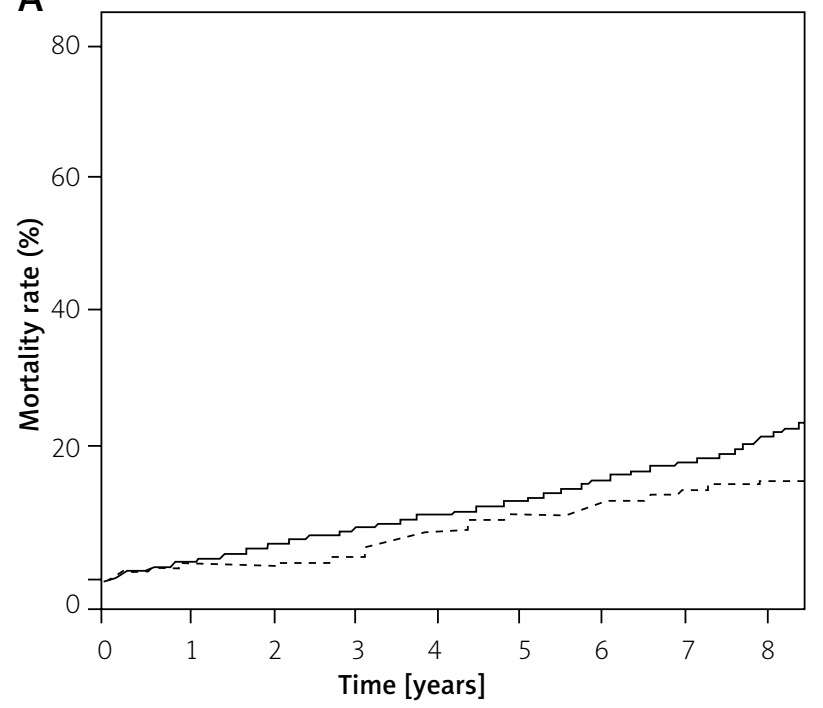

Long-term mortality $N(\%)$

$\left.\begin{array}{lr}\text { fTIMI 0-1 } & 205(25 \%) \\ \text { fTIMI } 2-3 & 32(17 \%)\end{array}\right\} p=0.03$

B

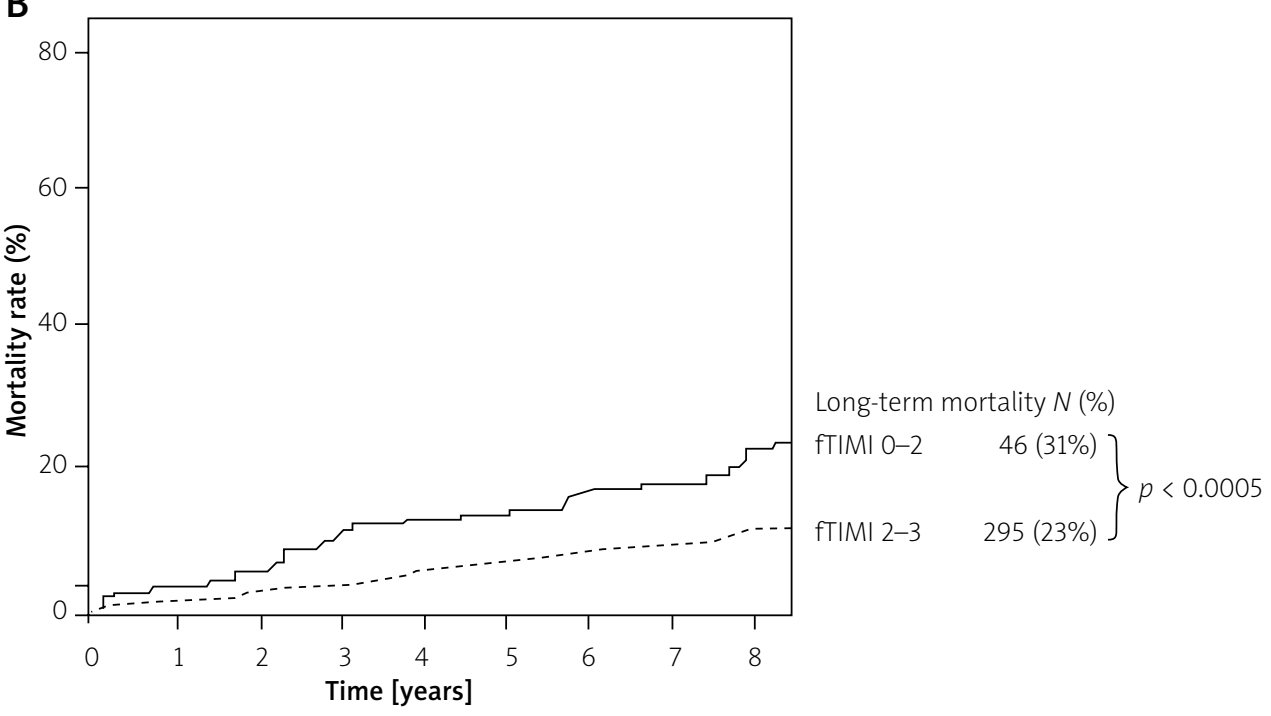

Figure 3. Kaplan-Meier curves of cumulative mortality in survivors of acute phase of STEMI according to: A - iTIMI flow, B - fTIMI flow 
or the "no reflow" syndrome. Therefore, even in patients with successful PCI there was a $24 \%$ increase in mortality when TIT exceeded $3 \mathrm{~h}$ compared to shorter TIT.

A similar phenomenon was seen in patients with TIT longer than $6 \mathrm{~h}$ and below that time. However, even in patients with TIT longer than $6 \mathrm{~h}$, survival of patients with successful PCI was significantly better than in those with $\mathrm{pPCl}$ failure. Our results strongly support the importance of achieving TIMI 3 flow as soon as possible and are in accordance with the 2017 ESC guidelines for STEMI treatment [20] that emphasised the significance of revascularisation during the first $3 \mathrm{~h}$ of ischaemia.

When the analysis was limited to survivors of the acute phase of STEMI, long-term mortality was significantly higher in patients with an occluded versus patent artery at baseline. Although the $\mathrm{PCI}$ result is a predictor of CV mortality in that group of patients, the difference in all-cause mortality rate is also prominent (Figure $3 \mathrm{~B}$ ).

In the whole group of patients, analysing factors associated with iTIMI flow we found that a patent IRA was observed more often in patients with a history of CAD and longer TIT. There were no differences between patients with a patent and an occluded IRA in the prevalence of renal dysfunction, diabetes mellitus, hypertension, heart failure, cardiogenic shock or multivessel disease. Previous studies demonstrated a lack of correlation between diabetes mellitus and patency of the IRA [21]. Nevertheless, it was shown that diabetic patients have a significantly narrower "normal" reference segment of the IRA than non-diabetic patients, suggesting more extensive, non-angiographically identifiable epicardial coronary artery disease which may already affect the prognosis [22].

The $\mathrm{PPCl}$ success depends on several factors. Our results are in accordance with previous studies [23] and confirm that the most critical factors related to the success of angioplasty are initial IRA patency, age, heart rate and smoking status. As shown before, current smokers were more likely to have better angiographic results. This correlation might be related to younger age and lower co-morbidity of smokers, which was explained before by different thrombus characteristics. It confirmed the "smoker's paradox".

The higher rate of $\mathrm{pPCl}$ failure in patients with advanced age, history of myocardial infarction, renal dysfunction, longer TIT, cardiogenic shock or lower initial TIMI flow contributes to worse prognosis of these patients.

Finally, pPCI failure was found to be a strong predictor of major bleeding, which may in part be associated with a higher rate of rescue abciximab administration.

\section{Conclusions}

Based on very long-term observation of a homogeneous, unselected group of patients we demonstrated a favourable prognosis of STEMI patients treated with $\mathrm{pPCl}$. Moreover, we confirmed the crucial role of timely and successful pPCl in 9-year outcomes, including in survivors of the acute phase. The mortality rate increased with TIT even in patients with $\mathrm{pPCl}$ success. Timely $\mathrm{PPCl}$ not only saves patients' lives acutely but also offers them survival for many years to come. Therefore, all efforts should be made with the aim of shortening the ischaemic time and achieving full recanalization of the IRA (fTIMI 3 flow).

\section{Conflict of interest}

The authors declare no conflict of interest.

\section{References}

1. Keeley EC, Boura JA, Grines CL, et al. Primary angioplasty versus intravenous thrombolytic therapy for acute myocardial infarction: a quantitative review of 23 randomised trials. Lancet 2003; 361: 13-20.

2. Yanamala CM, Bundhun PK, Ahmed A, et al. Comparing mortality between fibrinolysis and primary percutaneous coronary intervention in patients with acute myocardial infarction: a systematic review and meta-analysis of 27 randomized-controlled trials including 11429 patients. Coron Artery Dis 2017; 28: 315-25.

3. The GUSTO Investigators. The effects of tissue plasminogen activator, streptokinase, or both on coronary-artery patency, ventricular function, and survival after acute myocardial function. N Engl J Med 1993; 329: 1615-22.

4. Mehta RH, Harjai KJ, Cox D, et al. Clinical and angiographic correlates and outcomes of suboptimal coronary flow in patients with acute myocardial infarction undergoing primary percutaneous coronary intervention. J Am Coll Cardiol 2003; 42: 1739-46.

5. Boersma H, Maas AC, Deckers JW, et al. Early thrombolytic treatment in acute myocardial infarction: reappraisal of the golden hour. Lancet 1996; 348: 771-5.

6. Hirsch A, Verouden NJ, Koch KT, et al. Comparison of long-term mortality after percutaneous coronary intervention in patients treated for acute ST-elevation myocardial infarction versus those with unstable and stable angina pectoris. Am J Cardiol 2009; 104: 333-7.

7. Polańska-Skrzypczyk M, Karcz M, Bekta P, et al. Prognostic value of renal function in STEMI patients treated with primary $\mathrm{PCl}$ : ANIN Registry. Br J Cardiol 2013; 20: 65.

8. Kruk M, Przyłuski J, Kalińczuk L, et al. Clustering of admission hyperglycemia, impaired renal function and anemia and its impact on in-hospital outcomes in patients with ST-elevation myocardial infarction. Atherosclerosis 2010; 209: 558-64.

9. Levey AS, Coresh J, Balk E. National Kidney Foundation practice guidelines for chronic kidney disease: evaluation, classification, and stratification. Ann Intern Med 2003; 139: 137-47.

10. Piotrowski W, Polakowska M, Koziarek J, et al. Sudden cardiovascular death rate and ischaemic heart disease death rate changes during the 5-year period of 2003-2008. Kardiol Pol 2012; 70: 1225-34.

11. Uyarel H, Ayhan E, Cicek G, et al. Suboptimal coronary blood flow after primary percutaneous coronary intervention for acute myocardial infarction: incidence, a simple risk score, and prognosis. Coron Artery Dis 2012; 23: 98-104. 
12. Shiraishi J, Kohno Y, Sawada T, et al. Predictors of non optimal coronary flow after primary percutaneous coronary intervention with stent implantation for acute myocardial infarction. J Cardiol 2010; 55: 217-23.

13. Stone GW, Cox D, Garcia E, et al. Normal flow (TIMI-3) before mechanical reperfusion therapy is an independent determinant of survival in acute myocardial infarction: analysis from the primary angioplasty in myocardial infarction trials. Circulation 2001; 104: 636-41.

14. De Luca G, Ernst N, Zijlstra F, et al. Preprocedural TIMI flow and mortality in patients with acute myocardial infarction treated by primary angioplasty. JACC 2004; 43: 1363-7.

15. Joost A, Stiermaier T, Eitel C, et al. Impact of initial culprit vessel flow on infarct size, microvascular obstruction, and myocardial salvage in acute reperfused ST-elevation myocardial infarction. Am J Cardiol 2016; 118: 1316-22.

16. Van der Zee S, Baber U, Elmariah S, et al. Cardiovascular risk factors in patients with chronic kidney disease. Nat Rev Cardiol 2009; 6: 580-9.

17. Rabelink TJ, Zwaginga JJ, Koomans HA. Thrombosis and hemostasis in renal disease. Kidney Int 1994; 46: 287-96.

18. Malyszko J. Mechanism of endothelial dysfunction in chronic kidney disease. Clin Chim Acta 2010; 411: 1412-20.

19. Reimer KA, Lowe JE, Rasmussen MM, et al. The wave-front phenomenon of ischaemic cell death: myocardial infarct size versus duration of coronary occlusion in dogs. Circulation 1977; 56: 786-94.

20. Ibanez B, James S, Agewall S, et al. 2017 ESC Guidelines for the management of acute myocardial infarction in patients presenting with ST-segment elevation: The Task Force for the management of acute myocardial infarction in patients presenting with ST-segment elevation of the European Society of Cardiology (ESC). Eur Heart J 2018; 39: 119-77.

21. Prasad A, Stone GW, Stuckey TD, et al. Impact of diabetes mellitus on myocardial perfusion after primary angioplasty in patients with acute myocardial infarction. J Am Coll Cardiol 2005; 45: 508-14.

22. Chawla A, Chawla R, Jaggi S. Microvasular and macrovascular complications in diabetes mellitus: distinct or continuum? Indian J Endocrinol Metab 2016; 20: 546-51.

23. Cura FA, L'Allier PL, Kapadia SR. Predictors and prognosis of suboptimal coronary blood flow after primary coronary angioplasty in patients with acute myocardial infarction. Am J Cardiol 2001; 88: $124-8$. 